\title{
PENGEMBANGAN WISATA BERBASIS PERSEPSI PEGUNJUNG DI KAMPUNG AGROWISATA SENI BUDAYA PASANGGRAHAN UJUNG BERUNG, KOTA BANDUNG
}

\section{TOURISM DEVELOPMENT BASED ON VISITORS PERCEPTION IN PASANGGRAHAN ART AND CULTURAL VILLAGE, UJUNG BERUNG, BANDUNG}

\author{
Nurlena $^{1}$, Musadad ${ }^{2}$, dan Suryana H. Achmad ${ }^{3}$ \\ ${ }^{1,3}$ Telkom University \\ ${ }^{2}$ Universitas Riau \\ nurlena@tass.telkomuniversity.ac.id
}

\begin{abstract}
Pasanggrahan Art and Cultural Village is a village-based agritourism combining natural tourism with cultural tourism, especially Sundanese culture. The agritourism, located in Ciporeat Hamlet, Pasanggrahan Village, is included in the Bandung City Culture and Tourism Office's 2018-2023 Strategic Plan, meaning that this tourist destination is already in the local government's development plan. Therefore, this study aims to offer alternatives to the development of agritourism based on the visitor perceptions in order to offer a development concept to the related stakeholders. The data was collected through distributing questionnaires to 50 respondents and conducting interviews with the residents and those who understood the agritourism. The analysis results indicate that the visitors' bad perception clearly lies in the diversity of tourist attractions, souvenirs, places to eat, and roads within the destination. Therefore, this study focuses the alternative formulations or development efforts on the aspects of what to see, what to buy, what to do, what to arrive, dan what to stay.
\end{abstract}

Keywords: tourism development, agritourism, tourist village

ABSTRAK
Desa Seni dan Budaya Pasanggrahan adalah agrowisata berbasis desa yang
menggabungkan wisata alam dengan wisata budaya, khususnya budaya Sunda.
Agrowisata, yang terletak di Dusun Ciporeat, Desa Pasanggrahan, termasuk dalam
Rencana Strategis Dinas Kebudayaan dan Pariwisata Kota Bandung tahun 2018-2023, yang
berarti bahwa tujuan wisata ini sudah ada dalam rencana pengembangan pemerintah
daerah. Oleh karena itu, penelitian ini bertujuan untuk menawarkan alternatif untuk
pengembangan agrowisata berdasarkan persepsi pengunjung untuk menawarkan konsep
pengembangan kepada para pemangku kepentingan terkait. Data dikumpulkan melalui
penyebaran kuesioner kepada 50 responden dan melakukan wawancara dengan penduduk
dan mereka yang memahami agrowisata. Hasil analisis menunjukkan bahwa persepsi buruk
pengunjung jelas terletak pada keanekaragaman tempat wisata, suvenir, tempat makan, dan
jalanan pada area destinasi. Oleh karena itu, penelitian ini memfokuskan formulasi 
alternatif atau upaya pengembangan pada aspek what to see, what to buy, what to do, what to arrive, dan what to stay.

Kata kunci: pengembangan pariwisata, agrowisata, desa wisata

\section{PENDAHULUAN}

Kota Bandung merupakan salah satu kota di Indonesia yang serius mengembangkan pariwisatanya. Berbagai sektor telah dieksplorasi, baik wisat alam, wisata kota, tak terkecuali wisata seni dan budaya. Keseriusan Pemkot Bandung dalam mengembangkan pariwisatanya terlihat dari visi Kota Bandung sebagaimana tercantum dalam RPJMD Kota Bandung Tahun 2014 - 2018, yaitu "Mewujudkan Kota Bandung Sebagai Kota Seni Budaya Dan Tujuan Wisata Internasional 2018". Visi tersebut bukan tanpa alasan mengingat dalam RTRW yang ada, pengembangan pariwisata lebih diarahkan ke Bandung Timur. Sementara itu, sebagai langkah strategis, Pemerintah Kota Bandung telah menyediakan lahan sekitar \pm 6 Ha di Kelurahan Pasanggrahan, Kecamatan Ujung Berung, Kota Bandung yang direncanakan untuk pembangunan kawasan obyek wisata agro dan seni budaya atau Kawasan Wisata Seni Budaya Kreatif berwawasan lingkungan (Renstra Disbudpar Kota Bandung 2018-2023). Oleh karenanya, pemikiran pariwisata ini dimanifestasikan ke dalam sebuah agrowisata seni budaya yang memang bertujuan untuk mengakomodir konsep agrowisata (alam) dan seni budaya dalam satu tempat.

Upaya pengembangan wisata seni dan budaya di Kampung Agrowisata Seni Budaya Pasanggrahan Ujung Berung sudah sering dilakukan. Akan tetapi upaya yang dilakukan cenderung lebih menitikberatkan pada aspek produk wisata agro itu sendiri dan saran-saran dari para pelaku seni dan tokoh masyarakat. Berbagai saresehan atau seminar diadakan untuk menampung aspirasi dan kritik dari tokoh kesenian. Bahkan, dari sisi masyarakat (host) juga sudah dilakukan penelitian terkait dengan dampak pengembangan wisata du Kampung Agrowisata Seni Budaya Pasanggrahan Ujung Berung yang salah satu penemuannya adalah warga telah melakukan kampanye sadar wisata (Ginanjar, 2011).

Sampai pada titik ini, upaya pengembangan dari sisi wisatawan (guest) belum terlalu diakomodir. Padahal sebuah konsep pengembangan idealnya dilakukan dengan mempetimbangkan dua sisi, termasuk masyarakat sebagai host dan pengunjung sebagai guest. Oleh karena itu, penting untuk melakukan penelitian terkait aspek wisatawan sebagai salah satu bahan pertimbangan dalam merumuskan pengembangan lebih lanjut pada Kampung Agrowisata Seni Budaya Pasanggrahan Ujung Berung.

Mengingat belum optimalnya upaya pengembangan Kampung Agrowisata Seni Budaya Pasanggrahan Ujung Berung dari sisi pengunjung dan pentingnya pengembangan wisata budaya sebagaimana tertera dalam visi Kota Bandung, maka rumusan masalah dalam penelitian ini adalah:

a. Bagaimana persepsi pengunjung terhadap produk wisata di Kampung Agrowisata Seni Budaya Pasanggrahan Ujung Berung?

b. Bagaimana alternatif upaya pengembangan wisata budaya di Kampung Agrowisata Seni Budaya Pasanggrahan Ujung Berung?

Ada berbagai aspek pariwisata yang dapat dilakukan pengembangan. Namun, dalam penelitian ini aspek pengembangan dibatasi pada aspek 
pengembangan atraksi wisata yang meliputi what to see, what to do, what to buy, what to arrive, dan what to stay (Maryani, 1991). Oleh karena itu, pengembangan dalam penelitian ini difokuskan pada pemformulasian penawaran alternatifalternatif upaya pengembangan untuk kelima aspek pengembangan tersebut. Dengan demikian, tujuan dari penelitian ini adalah:

a. Mengetahui persepsi wisatawan terhadap produk wisata di Kampung Agrowisata Seni Budaya Pasanggrahan Ujung Berung.

b. Memberikan alternatif-alternatif upaya pengembangan wisata di Kampung Agrowisata Seni Budaya Pasanggrahan Ujung Berung.

Pengembangan pariwisata merupakan suatu rangkaian upaya untuk mewujudkan keterpaduan dalam penggunaan berbagai sumber daya pariwisata mengintegrasikan segala bentuk aspek di luar pariwisata yang berkaitan secara langsung maupun tidak langsung akan kelangsungan pengembangan pariwisata (Swarbrooke, 2002).

\section{METODE PENELITIAN}

Penelitian ini menggunakan metode kuantitatif, yang menurut Sugiyono (2010:14), adalah sebagai metode penelitian yang berlandaskan pada filsafat positivisme, digunakan untuk meneliti pada populasi atau sampel tertentu, teknik pengambilan sampel pada umumnya dilakukan secara random, pengumpulan data menggunakan instrumen penelitian, analisis data bersifat kuantitatif/statistik.

Populasi dalam penelitian ini adalah seluruh wisatawan yang mengunjungi Tahura Djuanda. Dikarenakan populasi dalam penelitian ini tidak tetap alias bergerak, maka penenetuan sampel dilakukan secara non-probability sampling menggunakan teknik accidental sampling, jadi siapapun (pengunjung) yang ditemui di lapangan akan dijadikan sampel. Jumlah responden dalam penelitian ini ditentukan sebanyak 50 orang, mengingat menurut Roscoe dalam Sugiyono (2010:91) mengemukakan bahwa jumlah sampel 30 sampai dengan 500 orang termasuk ukuran sampel yang layak dalam penelitian. Penentuan jumlah sampel ini juga didasarkan pada masih minimnya pengunjung yang mengunjungi agrowisata mengingat objek wisata ini baru saja dibuka.

Penelitian ini menggunakan kuesioner dan wawancara sebagai alat pengumpul data. Kuesioner dibuat berdasarkan indikator-indikator yang telah diformulasikan sebelumnya. Observasi juga dilakukan untuk mendokumentasikan situasi dan kondisi nyata di lapangan sehingga dapat digunakan untuk mendukung analisis data.

Setelah form isian kuesioner mengenai karakteristik pengunjung terkumpul dan terisi lalu dianalisis dengan menyajikan data dalam bentuk table (tabulasi data). Adapun rumus presentase yang digunakan untuk melihat berapa banyak kecenderungan frekuensi jawaban responden :

$\mathrm{P}=\frac{\mathrm{F}}{\mathrm{N}} \times 100 \%$

Keterangan:

$\mathrm{P}=$ Presentase

$\mathrm{F}=$ Frekuensi

$\mathrm{N}=$ Jumlah Sampel 
Hasil presentase lalu ditafsirkan sebagai berikut (Suharsimi, 2002):

$\begin{array}{ll}0 \%=\text { Tidak seorangpun } & 51 \%-74 \%=\text { Sebagaian besar } \\ 1 \%-24 \%=\text { Sebagian kecil } & 75 \%-99 \%=\text { Hampir seluruhnya } \\ 25 \%-49 \%=\text { Hampir setengahnya } & 100 \%=\text { Seluruhnya } \\ 50 \%=\text { Setengahnya } & \end{array}$

Skala ukur dalam penelitian ini menggunakan skala likert yaitu sangat buruk, buruk, netral, baik, dan sangat baik.

Setelah data terkumpul, selanjutnya dilakukan pemindahan dari daftar pertanyaan ke lembar tabulasi yang sudah disiapkan untuk selanjutnya diolah/dikalkulasi dengan microsoft excel. Data yang telah ditabulasikan selanjutnya dideskripsikan dengan diperkaya dengan data hasil wawancara dan observasi.

\section{HASIL PENELITIAN DAN PEMBAHASAN}

Agrowisata Seni Budaya Ujung Berung berada di Kampung Ciporeat, Desa Pasanggrahan, Kecamatan Ujung Berung, Kota Bandung. Kondisi saat ini terkait kondisi wisata yang ada disana adalah belum optimal dalam pengembangannya. Salah satu indikasinya adalah kurang terawatnya lokasi objek wisata agrowisata seni budaya ini. Hal ini terlihat dari observasi di lapangan dimana terlihat rerumputan tinggi tumbuh dimana-mana dan kondisi saung yang terlihat kotor.

Suatu kawasan atau objek wisata telah dibuka untuk umum dan sudah dimanfaatkan berbagai pihak untuk berbagai kegiatan seperti pertunjukan seni dan lain-lain, Agrowisata Seni Budaya memerlukan formulasi pengembangan ke depan agar dapat menarik lebih banyak pengunjung dan berkelanjutan (sustainable). Usaha pengembangan suatu destinasi wisata tersebut dapat didasarkan pada beragam pendekatan atau konsep. Dalam penelitian berusaha menggali alternatifalternatif usaha pengembangan dengan mendasarkannya pada persepsi pengunjung. Fokus persepsi pengunjung adalah pada produk wisata.

\section{Persepsi Pengunjung Terhadap Produk Wisata}

Sebagaimana dinyatakan oleh Middleton (2001), produk wisata meliputi empat aspek yaitu: atraksi, amenitas, aksesibilitas, dan kelembagaan. Berikut akan dikemukaan hasil kalkulasi persepsi pengunjung untuk masing-masing aspek tersebut (dinyatakan dalam persen) beserta penjelasannya.

a) Atraksi Wisata

Berikut adalah hasil rekapitulasi persepsi wisatawan pada aspek atraksi yang disajikan dalam bentuk persentase (\%).

Tabel 1. Persepsi Terhadap Komponen Atraksi

\begin{tabular}{|l|c|c|c|c|c|}
\hline Komponen Atraksi & $\begin{array}{c}\text { Sgt } \\
\text { Buruk }\end{array}$ & $\begin{array}{c}\text { Buru } \\
\mathbf{k}\end{array}$ & $\begin{array}{c}\text { Cuku } \\
\mathbf{p}\end{array}$ & Baik & Sgt Baik \\
\hline Keragaman daya tarik & $8 \%$ & $52 \%$ & $24 \%$ & 12 & $4 \%$ \\
\hline Kesejukan alam & $0 \%$ & $0 \%$ & $12 \%$ & $68 \%$ & $20 \%$ \\
\hline $\begin{array}{l}\text { Keindahan pemandangan } \\
\text { alam }\end{array}$ & $0 \%$ & $6 \%$ & $18 \%$ & $58 \%$ & $14 \%$ \\
\hline Aktivitas seni dan budaya & $0 \%$ & $4 \%$ & $22 \%$ & $52 \%$ & $22 \%$ \\
\hline
\end{tabular}




\begin{tabular}{|l|c|c|c|c|c|}
\hline Aktifitas masyarakat lokal & $2 \%$ & $12 \%$ & $54 \%$ & $26 \%$ & $6 \%$ \\
\hline Kebersihan kampung & $0 \%$ & $38 \%$ & $36 \%$ & $20 \%$ & $6 \%$ \\
\hline Keramahan warga & $0 \%$ & $4 \%$ & $8 \%$ & $72 \%$ & $16 \%$ \\
\hline
\end{tabular}

Berdasarkan Tabel 1, terlihat bahwa dari aspek keragaman daya tarik, pengunjung merasa kurang beragam. Hal ini dapat dipahami karena memang atraksi yang ditawarkan hanyalah pemandangan dan kesejukan alam (mayoritas persepsi baik) dan kegiatan seni budaya (mayoritas persepsi baik). Oleh karena itu diperlukan adanya usaha diversikasi produk agar atraksi menjadi semakin beragam. Untuk aktifitas seni dan budaya dipersepsikan dengan baik karena memang di agrowisata ini banyak dilangsungkan berbagai pertunjukan seni seperti festival syukuran lembur, pencak silat, dan lain-lain. Selain itu, di lokasi ini juga terdapat saung-saung yang besar untuk menunjang aktifitas-aktifitas tersebut. Komponen atraksi ini didukung oleh kebersihan kampung dan keramahan warga yang mendapat persepsi positif.

b) Amenitas

Rekapitulasi persepsi wisatawan berdasarkan komponen amenitas dapat dilihat pada Tabel berikut.

Tabel 2. Persepsi Terhadap Komponen Amenitas

\begin{tabular}{|l|c|c|c|c|c|}
\hline Komponen Amenitas & $\begin{array}{c}\text { Sgt } \\
\text { Buruk }\end{array}$ & Buruk & Cukup & Baik & Sgt Baik \\
\hline Toko suvenir & $12 \%$ & $80 \%$ & $8 \%$ & $0 \%$ & $0 \%$ \\
\hline Tempat makan & $18 \%$ & $50 \%$ & $28 \%$ & $4 \%$ & $0 \%$ \\
\hline Toilet & $0 \%$ & $12 \%$ & $24 \%$ & $52 \%$ & $12 \%$ \\
\hline Tempat parkir & $10 \%$ & $34 \%$ & $28 \%$ & $28 \%$ & $0 \%$ \\
\hline Tempat ibadah & $0 \%$ & $0 \%$ & $20 \%$ & $56 \%$ & $24 \%$ \\
\hline
\end{tabular}

Tabel 2 menunjukkan bahwa toko suvenir mendapat penilaian yang buruk mengingat tidak adanya toko suvenir. Untuk tempat makan juga mendapat persepsi buruk mengingat hanya ada satu warung kecil di agrowisata yang hanya menjual gorengan dan minuman. Tentu hal ini tidak dapat mengakomodasi keperluan konsumsi para pengunjung terlebih mereka yang menginginkan makanan berat ketika mereka lapar. Lahan parkir juga sebenarnya sudah ada namun belum ditata atau dipersiapkan secara baik. Untuk tempat ibadah, pengunjung dapat melaksanakan ibadah di masjid terdekat.

c) Aksesibilitas

Rekapitulasi persepsi wisatawan berdasarkan komponen aksesibilitas dapat dilihat pada Tabel berikut.

Tabel 3. Persepsi Terhadap Komponen Aksesibilitas

\begin{tabular}{|l|c|c|c|c|c|}
\hline Komponen Aksesibilitas & $\begin{array}{c}\text { Sgt } \\
\text { Buruk }\end{array}$ & $\begin{array}{c}\text { Buru } \\
\mathbf{k}\end{array}$ & $\begin{array}{c}\text { Cuku } \\
\mathbf{p}\end{array}$ & Baik & Sgt Baik \\
\hline Lokasi obyek & $0 \%$ & $4 \%$ & $10 \%$ & $78 \%$ & $8 \%$ \\
\hline Kondisi jalan di objek wisata & $12 \%$ & $56 \%$ & $22 \%$ & $10 \%$ & $0 \%$ \\
\hline
\end{tabular}




\begin{tabular}{|l|c|c|c|c|c|}
\hline Kondisi jalan menuju lokasi & $0 \%$ & $2 \%$ & $10 \%$ & $62 \%$ & $26 \%$ \\
\hline Transportasi menuju lokasi & $2 \%$ & $40 \%$ & $38 \%$ & $16 \%$ & $4 \%$ \\
\hline
\end{tabular}

Tabel 3 menunjukkan bahwa lokasi objek wisata agrowisata disukai terbukti dengan $78 \%$ mengatakan baik. Hal ini dapat dipahami mengingat lokasinya yang tidak terlalu jauh dari jalan raya (jalan raya ujung berung) dan tidak jauh dari pusat kota. Kondisi jalan juga dipersepsikan baik (62\%) mengingat jalan menuju lokasi sudah dicor dan halus. Namun, aspek aksibilitas ini mendapat persepsi buruk (56\%) untuk kondisi jalan di objek wisata. Dari hasil observasi terlihat bahwa jalan masih jalan tanah yang licin dan becek sehabis hujan dan jalan utama juga belum jadi. Kondisi ini perlu segera ditangani karena sangat tidak nyaman ketika berjalan di jalan yang sepertinya tidak disiapkan dengan serius. Untuk transportasi menuju lokasi, hampir setengahnya (40\%) mengatakan buruk kemungkinan karena angkot tidak boleh masuk ke desa pasanggrahan karena ada ojek.

\section{Upaya Pengembangan Agrowisata}

Terdapat beberapa jenis pengembangan menurut Swarbrooke (2002) yaitu:

a. Keseluruhan dengan tujuan baru, membangun atraksi di situs yang tadinya tidak digunakan sebagai atraksi.

b. Tujuan baru, membangun atraksi di situs yang sebelumnya telah berfungsi sbg atraksi

c. Pengembangan baru pada keberadaan atraksi yang dibangun untuk menarik pengunjung lebih banyak dan untuk membuat atraksi tersebut dapat mencapai pasar yang lebih luas, dengan meraih pangsa pasar yang baru.

d. Pengembangan baru pada keberadaan atraksi yang bertujuan untuk meningkatkan fasilitas pengunjung atau mengantisipasi meningkatnya pengeluaran pengunjung.

e. Penciptaan kegiatan-kegiatan baru atau tahapan dari kegiatan yang berpindah dari satu tempat ke tempat lain dimana kegiatan tersebut memerlukan modifikasi bangunan.

Di dalam perencanaan pengembangan wisata di agrowisata seni budaya ujung berung, dalam beberapa jenis pengembangan di atas, termasuk ke dalam pengembangan baru pada keberadaan atraksi dan kegiatan-kegiatan wisata dari sebuah objek wisata.

Agrowisata merupakan bagian dari objek wisata yang memanfaatkan usaha pertanian (agro) sebagai objek wisata. Tujuannya adalah untuk memperluas pengetahuan, pengalaman rekreasi, dan hubungan usaha dibidang pertanian. Melalui pengembangan agrowisata yang menonjolkan budaya lokal dalam memanfaatkan lahan, kita bisa meningkatkan pendapatan petani sambil melestarikan sumber daya lahan, serta memelihara budaya maupun teknologi lokal (indigenous knowledge) yang umumnya telah sesuai dengan kondisi lingkungan alaminya. Fandeli dan Nurdin (2005) mengatakan bahwa Agrowisata bergantung pada kualitas lingkungan alam dan sosial budaya yang baik dimana keduanya menjadi fondasi untuk meningkatkan ekonomi lokal dan kualitas kehidupan masyarakat yang timbul dari industri pariwisata. Mereka juga mengatakan bahwa Di kawasan agrowisata, wisatawan menikmati seluruh fasilitas yang ada, dan aktifitas kegiatan yang dapat memberikan pengetahuan baru dalam berwisata hanya 
saja tidak semua kebutuhan wisatawan tersebut dapat dipenuhi karena dalam beberapa hal mungkin terdapat harapan yang tidak sesuai dengan kondisi agrowisata yang bersangkutan.

Berdasarkan analisis pada persepsi pengunjung, alternatif-alternatif upaya pengembangan kampung agrowisata pasanggrahan yang mungkin dapat dilakukan adalah sebagai berikut:

\section{a. What to see}

Aspek what to see merupakan aspek yang penting dalam menunjang keragaman atraksi wisata mengingat keragaman daya tarik mendapat persepsi yang buruk dari pengunjung, yaitu 52\% atau sebagian besar pengunjung. Oleh karena itu, harus diupayakan beragam aktivitas what to see untuk membuat atraksi wisata lebih bervariasi sehingga tidak membuat pengunjung bosan.

Untuk konsep agrowisata, para pengunjung seharusnya diberi pengetahuan mengenai agrowisata yang lebih mendalam dengan cara menyaksikan (to see) secara langsung. Misalnya mereka melihat koleksi alat-alat pertanian yang khas dan bernilai sejarah atau naskah dan visualisasi sejarah penggunaan lahan maupun proses pengolahan hasil pertanian. Oleh karenanya, perlu adanya ruang display khusus yang memuat objek-objek diatas.

Adanya sesuatu yang dapat dilihat oleh pengunjung seperti kegiatan edukasi seperti wisata pendidikan bagi anak-anak sekolah, adanya museum yang alat dan produk kegitatan agro, festival dan event berkala lainnya (festival panen, festival makanan, festival bunga), dan pameran hasil-hasil pertanian. Untuk aktifitas semacam festival panen sudah ada, yaitu Gelar Syukuran Lembur yang diselenggarakan setiap bulan November.

Untuk konsep seni dan budaya, perlu diperbanyak atraksi yang menggambarkan budaya khas sunda seperti domba dan seni benjang yang harus dilakukan secara berkala. Oleh karenana, perlu dibuat kalender event agar masyarakat umum mengetahui jadwal pertunjukan seni dan budaya secara jelas. Selain itu, perlu diperkuat kelembagaan untuk mengelola aktifitas-aktifitas seperti ini. Sementara ini memang sudah ada seseorang yang membina kesenian ini akan tetapi belum terlalu settle.

\section{b. What to do}

Aspek selanjutnya yang merupakan unsur penting dalam menunjang variasi atraksi wisata adalah aspek what to do. Jadi aspek what to see dan what to do berkaitan erat dengan aspek atraksi.

Untuk konsep agrowisata, beberapa kegiatan atau aktifitas fisik dapat dilakukan oleh pengunjung adalah kegiatan pelatihan (workshop) seperti pembibitan, melukis, teknik membuat pupuk dan kompos, teknik kegiatan bercocok tanam, teknik memancing; aktifitas berbasis alam seperti birdwatching; aktifitas olahraga seperti memancing, berkuda, hiking, sepeda gunung; aktifitas pertanian seperti memberi makan binatang, farming; dan aktifitas rekreasi seperti berkemah, piknik, naik delman.

Selain konsep agrowisata, konsep seni budaya juga penting dikembangkan karena konsep awal dari objek wisata ini yang merupakan agrowisata seni budaya. Walaupun untuk aspek aktifitas seni budaya mendapatkan persepsi yang baik (52\%) dan sangat baik (22\%), tetap perlu dilakukan variasi aktifitas seni budaya. Beberapa 
yang dapat dilakukan untuk aspek what to do pada konsep seni budaya adalah belajar pencak silat, memainkan alat musik, dan belajar seni benjang. Saat ini memang ada aktifitas warga yang memang mampu menarik pengunjung ke agrowisata ini yaitu kegiatan merpati tinggi. Akan tetapi kegiatan ini hanya dilakukan para anggota komunitas pecinta burung merpati.

\section{c. What to buy}

Hampir seluruh pengunjung berpersepsi buruk terhadap suvenir/oleh-oleh (80\%). Hal ini tidak mengejutkan karena memang tidak ada toko suvenir khusus agrowisata seni budaya. Bahkan untuk tempat makan juga hanya terdapat satu buah itupun hanya menjual gorangan dan minuman dengan bentuk warung yang sangat sederhana (dari bambu). Mengingat persepsi pengunjung yang buruk terhadap what to buy ini, maka perlu diupayakan penjualan cenderamata, katering (makanan dan minuman), serta berbagai produk pertanian (menjual pupuk atau bibit pertanian).

Di samping agrowisata sebenarnya terdapat pabrik-pabrik rumahan tahu sumedang yang terkenal enak. Untuk menunjang konsumsi atau oleh-oleh pengunjung, tahu sumedang produksi rumahan ini dapat dimanfaatkan. Tahu tersebut bisa dijual di area agrowisata atau pengunjung diajak membeli tahu itu di tempat produksi karena lokasinya yang tidak jauh, sehingga bisa dijangkau dengan jalan kaki.

\section{d. What to arrive}

Aspek what to arrive berkaitan erat dengan aspek aksesibilitas. Untuk jalan menuju lokasi sudah mendapat persepsi positif dari pengunjung (62\%), namun hanya pada jalan di lokasi agrowisata yang masih jelek. Untuk menuju lokasi, kendaraan roda empat atau motor dapat digunakan. Namun, angkot tidak bisa masuk. Bagi pengunjung yang turun di jalan raya ujung berung dapat memanfaatkan objek yang berada di pertigaan jalan masuk ke desa.

Salah satu aspek what to arrive di agrowisata ini adalah belum adanya plang penunjuk jalan dan plang penunjuk lokasi objek agrowisata. Jadi pengunjung akan kebingungan ketika mencari lokasi objek wisata ini. Oleh karena itu, sudah semestinya dipasang plang penunjuk jalan agar pengunjung mudah untuk sampai (arrive) di agrowisata seni budaya ini.

\section{e. What to stay}

Dari hasil wawancara, memang tidak terdapat rumah khusus untuk menginap bagi para pengunjung (homestay). Namun, ketika ada pengunjung yang ingin menginap, maka mereka dapat memanfaatkan rumah-rumah kontrakan atau kos-kosan yang ada di Kelurahan Pasanggrahan. Biasanya ada saja pengunjung yang menginap ketika ada event besar karena event-event besar budaya sunda untuk wilayah bandung dipusatkan di agrowisata ini.

Tidak adanya homestay untuk menunjang akomodasi pengunjung tentunya kurang menunjung untuk kegiatan pariwisata di agrowisata ini. Selain untuk menunjang kenyamanan dan kepuasan pengunjung, kehadiran homestay juga dapat menunjang ekonomi warga lokal mengingat para pengunjung akan mengeluarkan uang langsung kepada pemilik rumah. Dengan demikian, sudah seharusnya keberadaan homestay ini diupayakan di Desa Pasanggarahan, khususnya Kampung Ciporeat. 


\section{KESIMPULAN}

Persepsi pengunjung terhadap produk wisata di agrowisata seni budaya pasanggarahan sangat beragam. Aspek-aspek yang terlihat jelas mendapatkan penilaian buruk adalah keragaman daya tarik, cindera mata, tempat makan, dan jalan di lokasi agrowisata. Oleh karena itu, hal-hal tersebut mendapatkan perhatian khusus dalam penelitian ini, artinya memerlukan upaya-upaya pengembangan lebih lanjut demi terciptanya kegiatan pariwisata yang optimal. Alternatif atau upaya pengembangan dalam penelitian ini lebih difokuskan pada aspek-aspek what to see, what to buy, what to do, what to arrive, dan what to stay. Sudah seharusnya semua pihak, termasuk pihak pemkot dan masyarakat, bekerjasama untuk memperbaiki dan meningkatkan kualitas objek wisata agrowisata tersebut demi kenyamanan dan kepuasan pengunjung serta demi kelestarian atau sustainability agrowisata. Kalau diperlukan, libatkan juga para akademisi dan praktisi di bidang pengembagan objek dan daya tarik wisata.

\section{DAFTAR PUSTAKA}

Disbudpar Kota Bandung. Renstra Disbudpar Kota Bandung 2018-2023. Tanpa Penerbit.

Fandeli, Chafid dan Nurdin, Muhammad. 2005. Pengembangan Ekowisata Berbasis Konservasi Di Taman Nasional. Yogyakarta: Fakultas Kehutanan UGM

Ginanjar, Lingga. 2011. Analisis Dampak Sosial Ekonomi Pembangunan Kawasan Agrowisata Seni Budaya Ujung Berung di Desa Pasanggrahan (Studi di Desa Pasanggrahan Kecamatan Ujungberung Kota Bandung). Skripsi. Universitas Islam Sunan Gunung Djati

Middleton VTC, Clarke J. 2001. Marketing in Travel and Tourism. Ed ke-3. Oxford: Elsevier

Sugiyono. 2010. Metode Penelitian Pendidikan Pendekatan Kuantitatif, kualitatif, dan R\&D. Bandung: Alfabeta

Swarbrooke, J.S. 2002. Development and Management of Visitor Attractions, 2nd ed. Oxford: Butterworth-Heinemann 